\title{
Research on Green Construction Management of Building Engineering
}

\author{
Yaoqian Sun ${ }^{1, a}$ \\ ${ }^{1}$ Jiyuan Vocational Technical College, Jiyuan, Henan, China, 459000 \\ a email
}

Keywords: Green Construction, Green Building, Construction Management

\begin{abstract}
Green construction is the future development direction of the construction field in China. It is necessary to do a good job in the construction of green construction management in the $t$ construction process to implement the concept of green construction. This paper discusses the connotation of green construction and gives four recommendations for the green construction management to provide some references for the relevant researchers.
\end{abstract}

\section{Introduction}

In recent years, China's construction industry has attained rapid development. A large number of construction projects into the building, and the construction industry for energy demand is very huge, to the original tense energy supply in china. Therefore, countries attach great importance to green construction in the project, so as to reduce energy consumption, alleviate the tense situation of energy green construction, the construction of the project, not only is the use of new construction technology, more is based on the existing construction technology, through strengthening the construction management, so as to improve the efficiency of resource utilization, reduce energy consumption. Green construction is based on the concept of modern environmental protection and resource efficiency, based on the construction of the implementation of the development of a modern environmental protection construction technology theory. Refers to the so-called green construction technology in construction process through the use of scientific management measures and advanced technology, efficient use of resources as the core, to the environmental priority principle, the negative effects as much as possible to reduce the construction on the environment caused by the pursuit of high efficiency and low consumption, environmental protection, overall planning, to maximize the quality of the project safety of hydropower energy building materials resource conservation, it relates to reduce the cycle using a plurality of sustainable cleaner production environmental protection material production of renewable resources. Green construction technology is the theoretical sublimation of the development of modern building technology. It is an important technical measure for people to build a harmonious ecological living condition and optimize the natural living environment.

\section{Connotation of Green Construction Management}

Saving Resources. Construction is very complex, involving a wide range and long duration, a large number of energy consumption throughout the process. Green construction is to see this point, to achieve energy saving". It contains two layers of meaning, not only to improve energy efficiency, reduce energy consumption, such as: indoor and outdoor lighting with low energy lamps; construction machinery with high environmental protection and energy saving, and through reasonable arrangement to improve the mechanical load rate and utilization rate; arrange according to the site, make full use of green energy. The material consumption of the construction industry in 
our country is staggering, and the green construction is required to reduce the material consumption of construction industry by saving material. It also contains two aspects: the first is to save material. The second is the use of environmentally friendly materials. Such as: to develop; rational stacking materials in site, reduce carry two times to minimize the loss of material; arrangement of path optimization of pipeline, material saving; other uses development waste, reuse the waste; optimization of energy saving and environmental protection, superior performance materials etc.. China's water shortage, the per capita water resources is low, and the spatial and temporal distribution is not uniform. Green construction vigorously promote water conservation measures to promote water conservation, new technology and new technology; strengthen the management of water, take feasible and reasonable, in accordance with the saving measures and alternative measures of environmental protection requirements, reduce or avoid the construction of water waste, efficient and reasonable utilization of water resources; both the open source and throttling, improve the water reuse rate. From the current situation of China, many people in China, in addition to the development of urbanization, construction land supply and demand tension. Green construction requirement to strengthen the overall planning of land use development of science, the ground and underground space, optimization of construction methods, reduce the temporary construction land, reduce engineering fill or soil, the comprehensive utilization of land, improve land use efficiency. In addition, try to reduce the disturbance of the land, the protection of the original green vegetation, greening the site, to prevent water and soil erosion and so on.

Protecting Environment. Today, the construction industry in the implementation of sustainable development strategy, environmental protection has become one of the objectives of green construction management. Mainly in accordance with the requirements of environmental management, the development of environmental protection plan, to take effective measures to control the construction of all kinds of pollution. At present, the society of our country has not formed the corresponding environmental protection consciousness in general, so there is not a good environmental protection atmosphere in the whole society. This leads to the construction management process. In addition to the workers engaged in the first line of construction workers most scientific and cultural quality is low. We do not have the concept of green construction, which will bring great resistance to the development of green construction management. Some of the economic benefits in the first place, for energy consumption and environmental pollution is not enough attention, which led to a lot of high energy consumption of construction projects approved. This has brought some difficulties to the development of green construction management. Plus the use of green construction in the short term tends to increase the cost of construction, also cannot get the corresponding income. The construction enterprise for green construction is often taking a negative management attitude. Pollution includes dust pollution, noise pollution, light pollution, water pollution, harmful gas pollution, solid waste and so on. Green construction should be made to minimize the impact of construction projects on the environment.

\section{Green Construction Management of Building Engineering}

Organization Management. The engineering building is not only in its comfortable and high quality function and the performance of the green building, but also the green construction in the construction process. If the process control does not reach the green construction, then build the green building is empty talk. Green construction requires the participation of all parties to assist with a project in the construction process, the parties to participate in the construction of green construction should have their respective responsibilities, the establishment of various types of green construction incentives. The construction party not only refers to the construction unit and the 
various sub-contractors, here the construction units design units supervision units at all levels of society supervision institutions shall be as part of green construction, fulfill their respective responsibilities. The construction unit should consider green energy-saving and environmental impact of the project in the project design stage; design unit in consideration of architectural design using function also deal with building energy-saving environmental protection materials have a full understanding, and as far as possible by. Supervision units as a permanent construction site supervision and inspection of the unit, the construction site of some of the impact of the surrounding environment and pollution practices should be raised, and urge the construction unit for rectification. Construction unit as the main operating unit of green construction, the project manager should be the first responsible person of green construction. We establish the corresponding management system of green construction. In accordance with the relevant provisions of the green construction, special supervision of the project green, not less than once a month to ensure that the green construction.

Material Management. We use the new building materials, and gradually expand the structural materials, decorative materials, structural components of the industrialization degree. Improve the field intensive operations, and effectively save resources, reduce environmental load. In the retaining wall and interior wall construction, a large number of cement perlite insulation brick is mainly used for connecting things building and gallery one to two layers of building envelope, improve building insulation effect, energy saving and environmental protection. Construction projects need to consume a large amount of building materials and energy, and the construction pollution is the most serious in the life cycle of the project. Therefore, the reuse of building materials has become the leading direction of the development of construction. Reduce energy consumption, protect all kinds of resources, make full use of all kinds of waste garbage is also the basic principles of building green construction. In the construction process it is not difficult to see a lot of energy saving and emission reduction measures in the construction process of the construction of the construction site such as precipitation recycling, disposal of construction waste after the construction site for regeneration of various energy saving measures, electricity, new building energy-saving materials. Construction process is gradually from a waste of resources construction process to a material reuse of resource conservation of the construction process. From the point of view of sustainable development of society, the reuse of building materials not only greatly reduce the waste of construction, but also provide more employment opportunities for the society in the process of material recycling. According to the national science and technology support policy, construction enterprises in the green construction of science and technology research and development efforts are gradually increasing, the recycling of resources and the construction site of energy-saving emission reduction measures.

Energy Management. We rely on the scientific and technological progress, technological innovation, to play the role of science and technology for energy saving and consumption reduction, through the program comparison, evaluation and other optimization measures, the formation of a scientific and reasonable construction scheme or construction organization design. Should reasonable arrangements for the construction sequence, working face, to reduce the number of construction equipment in the working area, adjacent operation area and make full use of common equipment resources; arrange the construction process, construction technology should first consider the consumption of electric energy or other energy consumption reduction. The rational allocation of construction equipment, try to make the best use of it, avoid the equipment rated power is far greater than the use of power or overloaded equipment used to reduce energy consumption phenomenon. We encourage the use of the country, the industry recommended 
energy-saving, efficient, environmentally friendly construction machinery and equipment and equipment; prohibit the use of obsolete products. Using the natural conditions of the site, reasonable design, production, living and office facilities of the shape, direction, spacing and window wall area ratio, so that it is a good day of sunlight, ventilation and lighting. The roof is provided with protective insulation layer. Office, living facilities prohibit the use of the country to eliminate products, priority selection of energy-saving products. Construction is also actively introducing new energy applications, including solar energy, geothermal energy, wind energy, ocean energy.

Environment Management. The construction environment is not only refers to the construction site of the mud, oil, dust of the small environment. In the modern civilization of the city, more refers to the construction of the construction site around the big environment. The acoustic noise of construction site dust pollution to the surrounding residents, suspended solids to affect the surrounding residents travel, night lighting construction on the surrounding residents of light pollution, the environmental pollution has aroused strong dissatisfaction and protest surrounding residents in the construction process. Therefore, in the construction process to reduce the disturbance of the surrounding environment of the construction site has become an important matter of green construction. The construction enterprise should formulate the anti-disturbing measures necessary. Reducing noise pollution is mainly the construction machinery sound source, in which the pile driver is the main pollution source of noise. The prohibition of night time construction is not only the main measure to reduce the noise, but also is the main measure to reduce the light pollution. In addition, construction enterprises can combine the local climate with appropriate construction methods, reasonable arrangement of the construction sequence, in order to reduce the construction site to the surrounding environment interference. In the workers living area to set up the propaganda column of the construction personnel to strengthen ideological education, a number of sets of garbage collection device, so that it is not random waste discarded materials to ensure that the living environment of workers and health. In the design and construction of sewage recycling rainwater channel construction site, circulation channel is connected with the sedimentation tank through the grille.

\section{Conclusion}

Currently, China's construction industry has many problems in the implementation of green construction management, such as inadequate attention and ineffective supervision. With the development of the improvement of the management concept and management strength, the green construction management in China has been gradually implemented in more and more buildings. We believe that in the near future, China's green construction management will make a great contribution to the development of China's construction industry and national economy.

\section{References}

[1] Li Minghui, Shanxi Architecture, Vol. 39(2013) No 6, p.233-235

[2] Long Weixiong, China New Technologies and Products, Vol. 20(2012) No 11, p.233-235

[3] Wu Jiansheng, China Homes, Vol. 8(2014) No 10, p.429-430

[4] Zhang Xiqian, Lin Lin, Wang Jun, Construction Technology, Vol. 40(2011) No 8, p.1-7 